\title{
Erratum to: NCL-CD30 staining of epithelial cells in the basal germinative layer of the epidermis and epithelial buds during foetal skin development
}

\author{
D. Tamiolakis $\cdot$ N. Papadopoulos $\cdot$ J. Venizelos $\cdot$ \\ M. Lambropoulou $\cdot$ P. Tsikouras $\cdot$ G. Koutsougeras $\cdot$ \\ S. Bolioti · M. Tsiapali $\cdot$ M. Menegaki $\cdot$ C. Kouskoukis
}

Published online: 8 October 2010

(C) Springer-Verlag 2010

\section{Erratum to: Clin Exp Med (2005) 5(4):184-189 DOI: 10.1007/s10238-005-0084-1}

This article [1] was submitted and subsequently published in Clinical and Experimental Medicine shortly after submitting and publishing analogous articles in [2,3] Romanian Journal of Biophysics and Acta Dermatovenereologica Alpina, Pannonica et Adriatica. Since the three articles published by the same research group resemble each other in that way that 90-95\% of the text is identical, we consider this as triplicate publication. The Editor-in-Chief and the publisher consider

The online version of the original article can be found under doi:10.1007/s10238-005-0084-1.

D. Tamiolakis $\cdot$ S. Bolioti $\cdot$ M. Tsiapali

Department of Cytology, General Hospital of Chania,

Crete, Greece

N. Papadopoulos $(\bowtie) \cdot$ M. Lambropoulou $\cdot$ M. Menegaki Department of Histology, Embryology, Democritus University of Thrace, Dragana, 68100 Alexandroupolis, Greece e-mail: npapad@med.duth.gr

J. Venizelos

Department of Pathology,

Ippokration Hospital of Salonica, Salonica, Greece

P. Tsikouras

Department of Obstetrics and Gynecology,

Democritus University of Thrace, Alexandroupolis, Greece

G. Koutsougeras

Department of Obstetrics and Gynecology,

General Hospital of Alexandroupolis, Alexandroupolis, Greece

C. Kouskoukis

Department of Dermatology, Democritus University of Thrace, Alexandroupolis, Greece this as a serious ethical misconduct and therefore the decision has been made to retract the article published in Clinical and Experimental Medicine.

Dr. D. Tamiolakis acknowledged full responsibility for this unfortunate situation. Prof. N. Papadopoulos, corresponding author of the article, declared himself and other co-authors unaware of the ethical infringement. He anyway agrees with the article retraction, is deeply sorry for any inconvenience this may have caused to the editorial and publishing staff of Clinical and Experimental Medicine and apologizes to the readers.

The online version of the original article can be found at http://dx.doi.org/10.1007/s10238-005-0084-1. This article should be considered as retracted.

\section{Bibliography}

1. Tamiolakis D, Papadopoulos N, Venizelos J, Lambropoulou M, Tsikouras P, Koutsougeras G, Bolioti S, Tsiapali M, Menegaki M, Kouskoukis C (2005) NCL-CD30 staining of epithelial cells in the basal germinative layer of the epidermis and epithelial buds during foetal skin development. Clin Exp Med 5(4):184-189

2. Tamiolakis D, Menegaki M, Nikolaidou S, Papadopoulos E, Bolioti S, Pavlidis P, Tzilivaki A, Papadopoulos N (2004) Occurrence of CD30 antigen on tissues and cells other than lymphoid origin. A study of human fetal skin in 8th, 10th, and 12th gestational weeks. Roman J Biophys 14:59-67

3. Tamiolakis D, Papadopoulos N, Venizelos J, Lambropoulou M, Tsikouras P, Koutsougeras G, Bolioti S, Tsiapali M, Karpouzis A, Kouskoukis C (2005) CD30 (Ki-1) molecule expression in human embryonal epithelial cells of the basal layer of the developing epidermis and epidermal buds and its potential significance for embryogenesis. Acta Dermatovenerol Alp Pannonica Adriat 14(3):85-90 